\section{THE INFLUENCE OF} RADIATION CROSS-LINKING ON MICRO-INDENTATION CREEP AND THE GEL
CONTENT OF POLYAMIDE MARTIN OVSIK, MARTIN REZNICEK, VOJTECH SENKERIK, MICHAL STANEK, LENKA HYLOVA

Tomas Bata University in Zlin, TGM 5555, 76001 Zlin, Czech Republic

DOI : 10.17973/MMSJ.2019_03_201861 e-mail : ovsik@utb.cz

Radiation Cross-linking is a process, at which the control change of polymers carried out of the purpose to reach the new polymeric materials with modified properties occurs. The submitted study deals with the influence of radiation doses on micro-creep properties of filled on non-filled polyamide 6.6. Micro-indentation creep of modified polyamide were measured using modern machinery DSI method (Depth Sensing Indentation) and were compared to the basic (nonirradiated) material. From the results it is evident, that the technology of radiation cross-linking has a positive influence on micro-creep properties of tested polyamide when the improvement of micro-creep properties was in the order of ten percent against the basic (non-irradiated) material. The influence of radiation cross-linking on micro-creep properties was confirmed by the measurement of the created crosslinked part (gel content) at individual tested radiation dose.

KEYWORDS

Polyamide 6.6, radiation, cross-linking, micro-indentation, creep, gel content

\section{INTRODUCTION}

Polyamide 6.6 (PA 6.6) belongs to the engineering semicrystalline polymers, which are mostly used for the production of packaging materials, automotive parts and electronic equipment. In these applications, PA 6.6 is almost used in the form of injection moulded parts, where commercial compounds as impact modifiers for improving low temperature performance and extend service life of the final product are used. These modifiers cause lowering of mechanical properties. It is desirable to enhance mechanical properties of the parts and the use of the fillers such as glass fibre enables the enhancement [Şanh 2011], [Behalek 2013].

There is another possibility how to improve further mechanical properties of PA GF, it is electron beam cross-linking. Crosslinking of PA is rather rare method of this type polymer modification, but there are significant changes which lead to the improvement of this polymer [Porubská 2011].

An important pointer of the success rate of cross-linking is a gel content. PA 6 irradiated at the doses of 200,400,600, 800, 1000 and $1200 \mathrm{kGy}$ showed the incipient gel formation at different temperatures approximately at the dose of $200 \mathrm{kGy}$. In comparison to PA 6.6 cross-linking was much higher for PA 6. The thermal behaviour of cross-linked PA 6 showed that melting and crystallization temperatures decreased with the increase of radiation dose. The percentage of crystallinity did not vary significantly up to the radiation dose of $1000 \mathrm{kGy}$ where the small decrease was recorded in comparison to PA 6.6 where crystallinity decreased significantly. In the area of mechanical behaviour of PA 6, was strongly affected by irradiation. Young's Modulus and stress at yield increased with the increase of the radiation dose, while stress at break and strain at break were strongly reduced [Adem 2013].

PA 6 modified with glycidyl methacrylate as a reactive mediator to cross-linking was modified by electron beam radiation at the doses of 5, 10, 20, 50, 100 and $200 \mathrm{kGy}$. Boo Young Shin found out that the gel content was measurable from the dose of $100 \mathrm{kGy}$, up this dose no changes were recorded in comparison to non-irradiated PA 6 . Tensile modulus and tensile strength had the significant increase at the dose of $200 \mathrm{kGy}$ in comparison to non-irradiated sample and elongation at break had the biggest increase at the dose of $10 \mathrm{kGy}$, subsequently started to drop [Shin 2015] .

Mária Porubská dealt with PA 6 GF $30 \%$ and its properties after electron beam radiation at the doses of 50, 100, 200, 300 and 500 kGy. She compared PA 6 GF $30 \%$ and PA 6 after irradiation. The highest difference she found at Young's modulus. Pure PA 6 had the highest value of this modulus at the dose of $500 \mathrm{kGy}$ around $2800 \mathrm{MPa}$ while PA $6 \mathrm{GF} 30 \%$ at the same dose around $8800 \mathrm{MPa}$ and also Vicat softening temperature differed significantly, its highest values were found at the radiation dose of $50 \mathrm{kGy}$, for PA 6 was $190^{\circ} \mathrm{C}$ and for PA 6 GF $30 \%$ was slightly under $210^{\circ} \mathrm{C}$ [Porubská 2014].

A lot of research papers have been concentrated on thermal and mechanical properties of cross-linked polyamides filled with glass fibres, but there is a gap in the area of microindentation creep behaviour measured using Micro-Combi Tester. This article deals with these measurement, which is very important to long-time life time of the final product.

\section{EXPERIMENTAL}

\subsection{Material}

For this experiment Polyamide 6.6 non-filled and filled with $30 \%$ glass fibre was used (Table 1 ). The material already contained the special cross-linking agent TAIC - triallyl isocyanurate ( 6 volume $\%$ ), which should enable subsequent cross-linking by ionizing $\beta$-radiation.

\begin{tabular}{ccc}
\hline Type of Polymers & Trade Name & Company \\
\hline Polyamide 6.6 & PA 6.6 FRIANYL A63 VN & Frisetta \\
Polyamide 6.6 with & PA 6.6 FRIANYL A63 VN GV & \\
30\% of glass fiber & 30 schwarz 9005 & Frisetta \\
\hline
\end{tabular}

Table 1: Tested polymers

\subsection{Sample preparation}

\begin{tabular}{ccc}
\hline Parameters & PA 6.6 & PA 6.6 30 \% GF \\
\hline Injection Pressure (Mpa) & 80 & 65 \\
Cooling Time $(\mathrm{s})$ & 17 & 17 \\
Mould Temperature $\left({ }^{\circ} \mathrm{C}\right)$ & 70 & 70 \\
Zone $1\left({ }^{\circ} \mathrm{C}\right)$ & 220 & 220 \\
Zone $2\left({ }^{\circ} \mathrm{C}\right)$ & 250 & 250 \\
Zone $3\left({ }^{\circ} \mathrm{C}\right)$ & 270 & 270 \\
Zone $4\left({ }^{\circ} \mathrm{C}\right)$ & 280 & 280 \\
\hline
\end{tabular}

Table 2: Process parameters 
The samples were made using injection molding technology on an Arburg Allrounder $470 \mathrm{H}$ injection molding machine (Loßburg, Germany). The normalized specimens, with dimensions of $(80 \times 10 \times 4) \mathrm{mm}$, were used (Figure 1.). The process parameters were set according to the manufacturer's recommendations; see Table 2 .

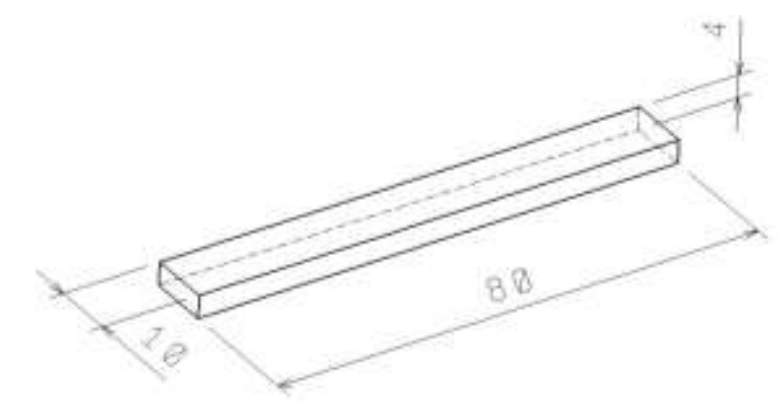

Figure 1: Dimension of sample

\subsection{Irradiation}

The cross-linking causes the connection of polymeric chains to each other, the most often using covalent bonds to form the spatial network. Given the ever increasing performance requirements of polymer properties the importance and need for its modification increase proportionally. Test bodies were irradiated under industrial conditions on commercially available irradiation device in a wider range of radiation doses $(0,33,66,99,132,165$ and $198 \mathrm{kGy})$ in comparison to doses corresponding to the experience in the practice. Irradiation of the tested polyamidu 6.6 was performed with the kind help of BGS Germany (Wiehl, Germany), in the BGS Wiehl plant, using accelerated electrons. A Rhodotron R E-beam accelerator (Tongeren, Belgium) with $10 \mathrm{MeV}$ electron energy was used for this purpose. Each passage under the accelerator scanner is equal to $33 \mathrm{kGy}$.

\subsection{Gel Content}

A gel (content) test is performed in order to determine the non-dissolved gel content of the given material-according to the ASTM D 2765 standard-Test Method C. A portion of $0.5 \mathrm{~g}$ (of electron-beam irradiated PA 6.6 and PA $6.630 \%$ GF material) weighed with a precision of five decimal places on a "SWISS MADE EP 125 SM" weighing apparatus (Dietikon, Switzerland) was mixed with $100 \mathrm{~mL}$ of solvent. Xylene was used on the PA 6.6 because it dissolves the amorphous part of this material, and the cross-linking part does not dissolve. The mixture was extracted for $24 \mathrm{~h}$. Then, the solutes were separated by distillation. After removing the residual xylene, the cross-linked extract was dried for $8 \mathrm{~h}$, in a vacuum, at 100 ${ }^{\circ} \mathrm{C}$. The dried and cooled residue was weighed again with a precision of five decimal places and compared to the original weight of the portion. The result is stated in percentage as the degree of cross-linking [Ovsik 2016]:

$$
G_{i}=\frac{m_{3}-m_{1}}{m_{2}-m_{1}} \cdot 100
$$

where $G_{i}$ is the degree of cross-linking of each specimen expressed in percentage, $m_{1}$ is the weight of the cage and lid in milligrams, $m_{2}$ is the total of the weights of the original specimen, cage and lid in milligrams, and $m_{3}$ is the total of the weights of the residue specimen, cage and lid in milligrams [Manas 2018].

\subsection{Micro-indentation test (creep)}

Micro-indentation tests were performed using a microindentation tester (Micro Combi Tester) (Figure 2), made by Anton Paar (Graz, Austria), according to the CSN EN ISO 14577 standard. The tip is made of diamond and its shape is that of a cube corner (Vickers). In the present study, the maximum load used was $1 \mathrm{~N}$, and the loading rate (and unloading rate) was 2 $\mathrm{N} / \mathrm{min}$. The holding time was $21600 \mathrm{~s}$. The measurement was carried out using the depth sensing indentation (DSI) method. This method enables one to measure the force acting on the indentor, as well as the displacement of the indentor's tip.
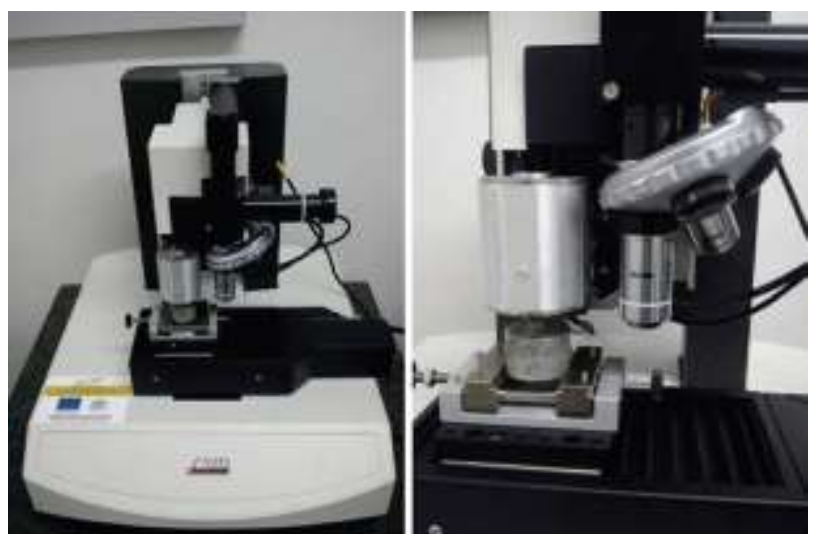

Figure 2: Micro-indentation tester

Determination of indentation creep $\mathrm{C}_{\mathrm{T}}$, where $\mathrm{h}_{1}$ is the indentation depth at time $t_{1}$ of reaching the test force (which is kept constant), $h_{2}$ is the indentation depth at time $t_{2}$ of holding the constant test force [Oliver 2004], [Pharr 1998]:

$$
C_{I T}=\frac{h_{2}-h_{1}}{h_{1}} \cdot 100
$$

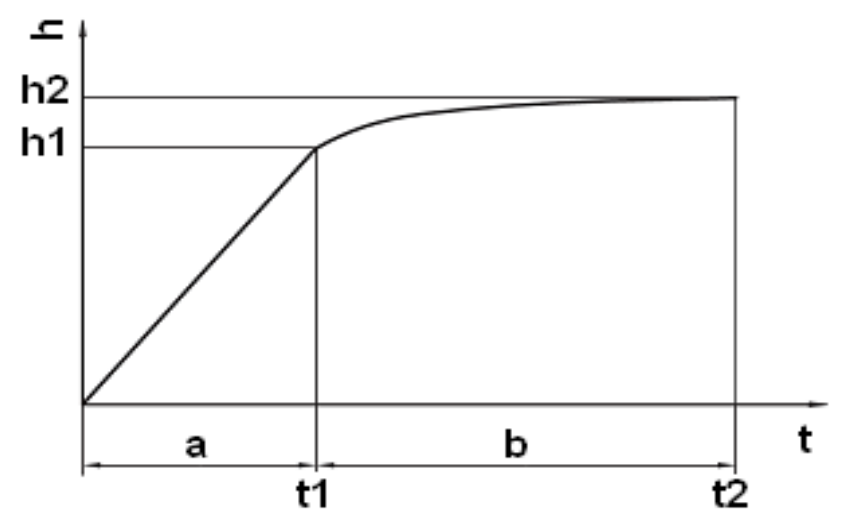

Figure 3: Expression of indentation creep, a - Application of the test force, $b$ - Test force kept constant from $t_{1}$ to $t_{2}$.

Measurement of all above mentioned properties was performed 10 times to ensure statistical correctness.

\section{RESULTS AND DISCUSSION}

Radiation cross-linking includes a process of the chemical bonds formation between individual molecules or individual particles of one molecule. It is a process, during which the material is exposed to ionizing radiation to produce free radicals. During radiation cross-linking, the main assumption is 
the formation of cross-links, not scission of macromolecules degradation, after ionizing radiation. Both processes, crosslinking and degradation run in parallel. The detection if predominant cross-linking or degradation was determined by the gel content test.

The gel content test is carried out for the purpose of nonfilterable phase content measurement of the given material according EN ISO 579. The determination of the gel content at polyamide 6.6 in the dependence of applied dose of radiation is evident from Figure 4. Non-crosslinked (basic) material has zero value of the gel. The higher dose of radiation, the higher gel content. The highest value of the gel content was measured at non-filled polyamide 6.6 and also at polyamide 6.6 filled with $30 \%$ of glass fibres at the dose of $132 \mathrm{kGy}$. At higher doses of radiation the small decrease of gel content at both material occurred. It is caused because of predomination of the degradation over cross-linking at both materials. The results of the gel content copy exactly the micro-indentation creep results, when the most cross-linked material showed the best values of micro-indentation creep. The decrease of the gel content show the worsening of micro-indentation properties.

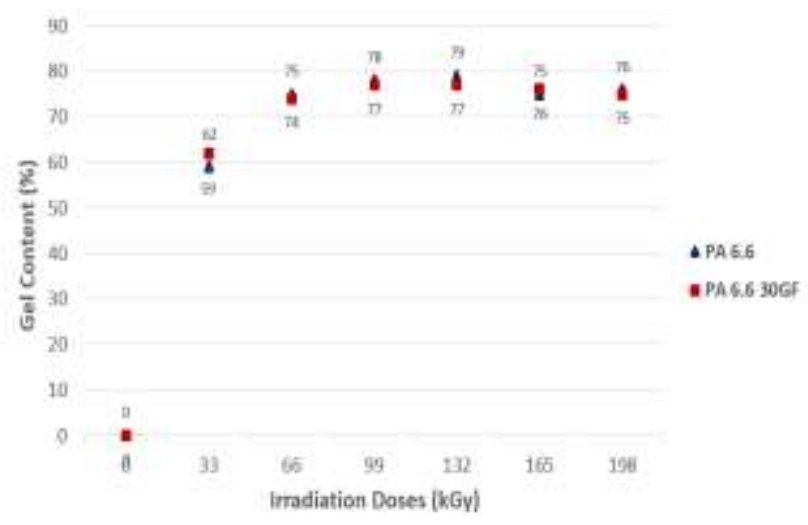

Figure 4: Gel content of tested PA 6.6

The DSI method is determined not only for micro-indentation creep of polymers. From the results it is possible to obtain a lot of other results for comprehensive assessment of the mechanical behaviour of polymers. The basic source of information the indentation characteristics obtained during measurement recorded the run of loading force in the dependence of the depth of the indenter penetration is. The importance of indentation characteristics is going to be presented on the base of the change of mechanical behaviour of tested polymers generated by radiation cross-linking comparison.

From Figure 5 and 6 , there is evident the change of the properties of non-filled polyamide 6.6 and polyamide 6.6 filled with $30 \%$ of glass fibres with addition of cross-linking agent before and after irradiation by different doses. Figure 5 characterizes the dependence of the indentation depth on time of the application of the constant loading force, while indentation curves give the possibility to obtain indentation hardness, indentation modulus and the size of deformation, elastic, plastic and total work needed to formation of the indentation. The time run of the indentation depth is the important run of measurement for the purpose of the determination of the creep behaviour of polymers (indentation creep), which is determined from the difference of the loading after achieving of the indentation depth which is holding on the constant level and after time when the indentation depth was held on the constant level.

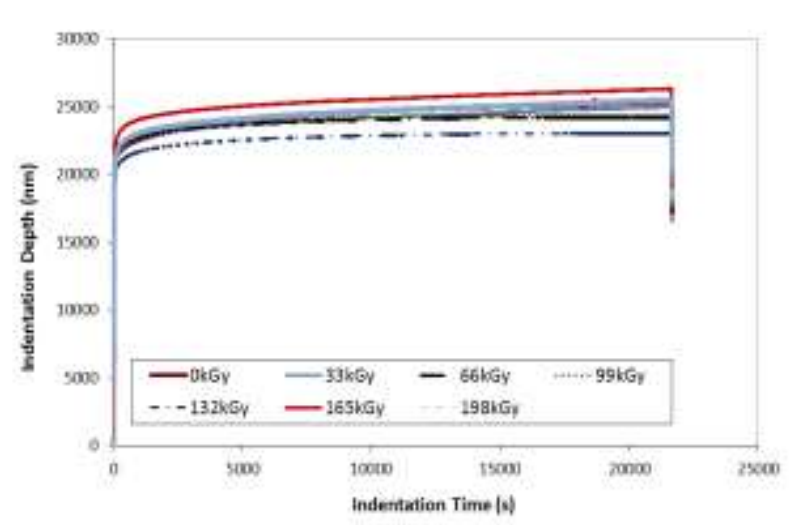

Figure 5: Indentation characteristic of tested PA 6.6

Indentation curves show that the radiation cross-linking influences positively the creep behaviour (indentation creep) of tested polyamide 6.6 filled with $30 \%$ of glass fibres how is apparent from Figure 6 . The biggest depth was achieved at the non-irradiated PA 6.6 filled with $30 \%$ of glass fibres (25 000 $\mathrm{nm}$ ), what was proved by the highest value of microindentation creep, while irradiated materials showed the decrease of the depth (approximately $16000 \mathrm{~nm}$ ), what was proved by the improvement of creep properties.

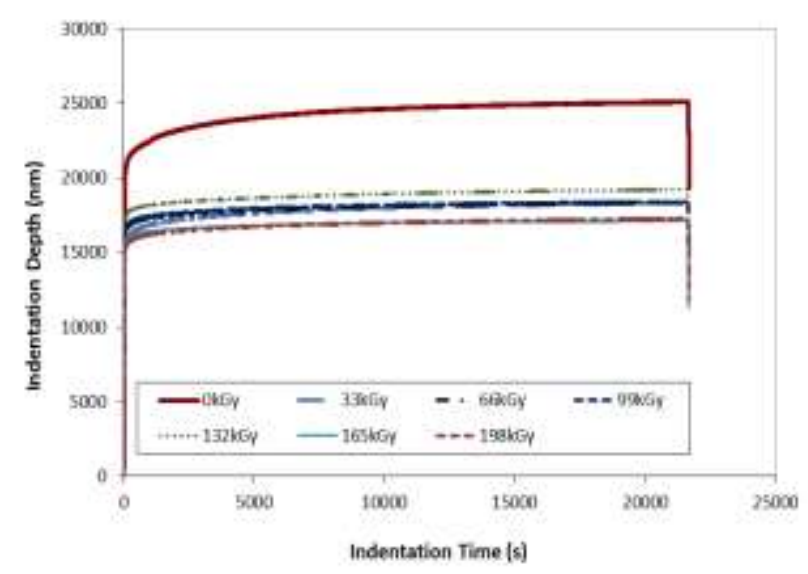

Figure 6: Indentation characteristic of tested PA 6.6 30\% GF

The results show that radiation cross-linking influences positively the creep behaviour (indentation creep) of tested polyamide 6.6 how is evident from Figure 7. From the results obtained using Instrumental test of hardness was proved that the highest value of indentation creep was measured at nonirradiated polyamide $6.6(33.8 \%)$. The lowest value of indentation creep was at non-filled polyamide 6.6 irradiated at the dose of $99 \mathrm{kGy}(23.7 \%)$, which was $43 \%$ lower in comparison with non-irradiated PA 6.6. At higher doses of radiation the significant increase of the indentation creep was measured, which the degradation of tested polymer could cause, mainly in surface layers. After comparison of indentation creep with the gel content (Figure 4) is evident, that results correspond. The higher gel content, the highest drop of indentation creep.

Similar results of micro-indentation creep was measured at polyamide 6.6 filled with $30 \%$ of glass fibres. The highest values of indentation creep were measured at non-irradiated material (32\%) the same like at non-filled polyamide 6.6 . The best values of micro-indentation creep of tested irradiated polyamide 6.6 filled with $30 \%$ of glass fibres were at the dose of $165 \mathrm{kGy}$ (16.8\%). In comparison with non-irradiated material the improvement of micro-creep properties was 90 $\%$. At the highest value of radiation dose the slight increase of 
micro-indentation was measured. At non-filled polyamide 6.6 and at filled polyamide 6.6 the increase of micro-indentation creep at the dose of $198 \mathrm{kGy}$ was caused by the degradation, which was confirmed by the gel content.

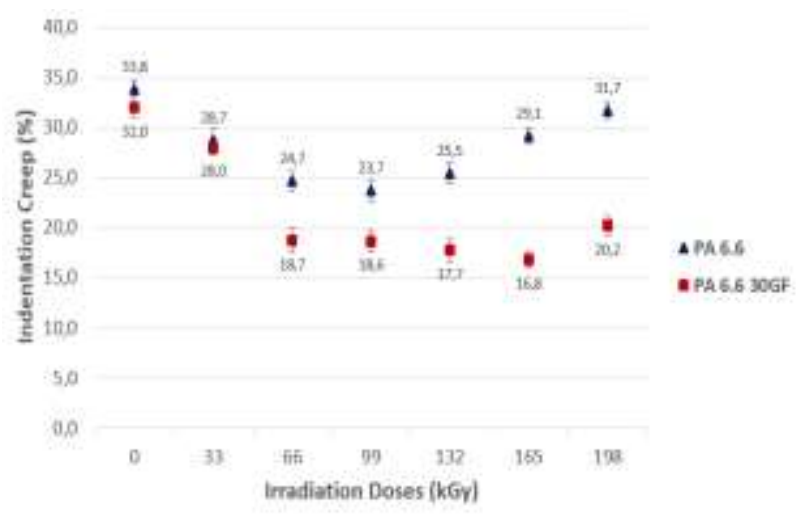

Figure 7: Micro-indentation creep of tested PA 6.6

\section{CONCLUSIONS}

The aim of this work was to describe the influence of ionizing beta radiation dose on the change of micro-indentation creep and the gel content studied at polyamide 6.6. The measurements were measured with the repeatability at least 10. Also a gross error check was performed including the normit test. All presented conclusions are determined on the basis of sample files of frequencies of given repeatability.

From the graphical comparison of the changes of all studied properties of irradiated and non-irradiated test samples it can be stated that obtained measurement results confirmed the influence of ionizing radiation on the above mentioned properties (in the order of tens of percent) and showed significant differences in changes in the observed properties. For non-filled polyamide 6.6, the improvement in micro-creep properties was measured by $43 \%$ at the dose of $99 \mathrm{kGy}$. At irradiated polyamide 6.6 filled with glass fibres, the creep properties improved by $90 \%$ at a radiation dose of $165 \mathrm{kGy}$. This improvement was due to the cross-linking of the test material with radiation. At higher doses of radiation, the creep properties were measured, which is due to the degradation process due to high radiation doses. Whether crosslinking or degradation has been confirmed by testing the gel content.

As can be seen from the results of this study, during ionizing radiation, structural material such as polyamide 6.6 can move from the field of structural materials to the area of high-tech polymers.

\section{ACKNOWLEDGMENTS}

This work was supported by the European Regional Development Fund under the project CEBIA-Tech Instrumentation No. CZ.1.05/2.1.00/19.0376 and by the Ministry of Education, Youth and Sports of the Czech Republic within the National Sustainability Program project no. LO1303 (MSMT-7778/2014). Moreover, it was supported by the Internal Grant Agency of TBU in Zlin: no. IGA/FT/2019/002.

\section{REFERENCES}

[Adem, 2013] Adem, E., et al. Polyamide-6: The effects on mechanical and physicochemical properties by electron beam irradiation at different temperatures. Radiation Physics and Chemistry. Vol. 97. 2014. pp. 165-171.
[Behalek 2013] Behalek, L. and Dobránsky, J. Conformal cooling of the injection moulds. Applied Mechanics and Materials. Vol. 308 (2013). pp. 127-132. ISSN 1660-9336.

[Dobransky 2013] Dobransky, J., et al. Comparison of Cooling Variants by Simulation Software. Advanced Materials Research. Vol. 801 (2013). pp. 75-80. ISSN 1022-6680.

[Manas 2018] Manas, D., et al. The Effect of Irradiation on Mechanical and Thermal Properties of Selected Types of Polymers, Polymers, 10 (2018), 158.

[Oliver 2004] W.C. Oliver, W.C. and Pharr, G.M. Measurement of Hardness and Elastic Modulus by Instrumented Indentation. Journal of Materials Research 19 (1), (2004), 1564 - 1583.

[Ovsik 2016] Ovsik, M., et al. he behaviour of cross-linking filled PBT measured by nano-hardness, MM Science Journal, 2016 (2016), 1110-1113-510.

[Pharr 1998] Pharr, G.M. Measurement of mechanical properties by ultra-low load indentation. Materials Science and Engineering (1998).

[Porubska, 2011] Porubská, M., et al. On gel determination in PA6-glass fiber composites. Polymer Testing. Vol. 30. 2011. pp. 472-477.

[Porubska, 2014] Porubská, M., et al. The effecto of electron beam irradiation on properties of virgin and glass fiberreinforced polyamide 6. Radiation Physics and Chemistry. Vol 102. 2014. pp. 159-166.

[Şanh, 2011] Şanh, S., et al. Isothermal crystallization kinetics of glass fiber and mineral-filled polyamide 6 composites. J. Mater. Sci. Vol. 47. 2011. pp. 3052-3063.

[Shin, 2015] Shin, B.Y., et al. Rheological and mechanical properties of polyamide 6 modified by electron-beam initiated mediation process. Radiation Physics and Chemistry. Vol. 112. 2015. pp. 88-96.

\section{CONTACTS}

Ing. Martin Ovsik, Ph.D.

Tomas Bata University in Zlin, TGM 5555, 76001 Zlin, Czech Republic +420576035100, ovsik@utb.cz

Ing. Martin Reznicek, Ph.D.

Tomas Bata University in Zlin, TGM 5555, 76001 Zlin, Czech Republic mreznicek@utb.cz

Ing. Vojtech Senkerik, Ph.D.

Tomas Bata University in Zlin, TGM 5555, 76001 Zlin, Czech Republic vsenkerik@utb.cz

doc. Ing. Michal Stanek, Ph.D.

Tomas Bata University in Zlin, TGM 5555, 76001 Zlin, Czech Republic stanek@utb.cz

Ing. Lenka Hylova

Tomas Bata University in Zlin, TGM 5555, 76001 Zlin, Czech Republic hylova@utb.cz 